Удк 636.068

https://doi.org/10.32634/0869-8155-2020-341-9-46-49

Тип статьи: Оригинальное исследование

Type of article: Original research

Кленовицкий П.М.,

Волкова Н.А.,

Иолчиев Б.С. *,

Раджабов Н.А.

ФГБНУ «Федеральный научный центр животноводства - ВИЖ имени академика Л.К. Эрнста». 142132, Московская область, Городской округ Подольск, пос. Дубровицы, дом 60.

E-mail:baylar1@yandex.ru

Ключевые слова: архар (Ovis ammon), гибриды, кластерный анализ, овцы, типы шерстных волокон.

Для цитирования: Кленовицкий П.М. Волкова Н.А., Иолчиев Б.С., Раджабов Н.А. Сравнительная характеристика шерстного покрова у потомков памирских тонкорунных овец от гибридного баранапроизводителя - 3/4 Романовская (РОМ) × 1/4 Архар (АРХ) исходных форм овец. Аграрная наука. 2020; 341 (9): 46-49.

https://doi.org/10.32634/0869-8155-2020-341-9-46-49

Конфликт интересов отсутствует

Pavel M. Klenovitsky,

Baylar S. Iolchiev,

Natalya A. Volkova,

Najbuddin A. Rajabov

Federal Science Center for Animal Husbandry named after Academy Member L.K. Ernst E-mail: baylar1@yandex.ru

Key words: small cattle, pyroplasmidosis Phorticarb ${ }^{\circledast} 10 \%$, therapeutic efficacy.

For citation: Klenovitsky P.M., Iolchiev B.S. Volkova N.A., Rajabov N.A. Comparative characteristics of wool cover in descendants of Pamir fine-wooled sheep from a hybrid ram 3/4 Romanovskaya (RUM) × 1/4 Argali (ARCH) of the from the parent forms of sheep. Agrarian Science. 2020; 341 (9): 46-49. (In Russ.)

https://doi.org/10.32634/0869-8155-2020-341-9-46-49

There is no conflict of interests

Сравнительная характеристика шерстного покрова у потомков памирских тонкорунных овец от гибридного барана-производителя 3/4 Романовская (POM) × 1/4 Архар (APX) исходных форм
овец

\title{
PEЗЮME
}

Актуальность и материал исследований. Цель работы - анализ влияния метизации овец памирской тонкорунной породы с гибридом архара и романовской овцы, несущим 3/4 крови романовской овцы и 1/4 крови архара на долю и диаметр шерстных волокон разного типа. Исследования проведены в 2016-2018 годах. Овцематок памирской тонкорунных породы осеменили спермой барана-производителя, несущего 3/4 крови романовской овцы и 1/4 крови архара. Получили и исследовали 5 гибридных баранчиков. В качестве контроля исследовали по 10 чистопородных сверстников памирской тонкорунной породы. Отбор средних проб шерсти у годовалых баранчиков и ее анализ проводили в соответствии с ГОСТ 17514-93. Сходство характеристик шерстного покрова оценивали на основании эвклидовых расстояний между признаками в программе SSPS. Статистическую обработку осуществляли в программе Microsoft Excel 2007.

Результаты. Доля пуховых волокон и их толщина у баранчиков памирской тонко-

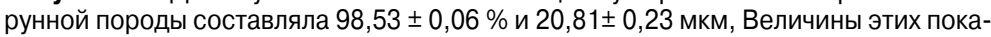
зателей у гибридов памирской тонкорунной были равны 92,31 \pm 0,13 \% и 21,90 \pm 0,24 мкм. Кластерный анализ сходства характеристик шерстного покрова у овец исследованных генотипов на основе расчета эвклидовых расстояний, выполненный в программе SPSS, выявил два кластера. Первый кластер образуют овцы памирской тонкорунной породы и их потомки от гибрида, несущего 1/4 крови архара и 3/4 крови романовской овцы. Во второй кластер входят остальные генотипы овец. Внутри этого кластера выделяется подкластер, объединяющий архара (архар) и его гибридов двух поколений. В пределах подкластера наиболее близки архар и его гибрид первого поколения с романовской овцой.

\section{Comparative characteristics of wool cover in descendants of Pamir fine-wooled sheep from a hybrid ram 3/4 Romanovskaya (RUM) $\times$ $1 / 4$ Argali (ARCH) of the from the parent forms of sheep}

\begin{abstract}
Relevance and research material. The aim of the work is to analyze the influence of mestization of Pamir fine-wooled sheep with a hybrid of argali and Romanov sheep, carrying $3 / 4$ of the blood of Romanov sheep and 1/4 of the blood of argali on the proportion and diameter of wool fibers of different types. The research was conducted in 2016-2018. Lambs of the Pamir fine-fleeced breed were inseminated with the sperm of a RAM-producer bearing 3/4 of the blood of the Romanov sheep and 1/4 of the blood of the argali. 5 hybrid rams were obtained and studied. As a control, 10 purebred peers of the Pamir fine-wool breed were studied. The selection of average wool samples from one-year-old rams and its analysis were carried out in accordance with GOST 17514-93. Similarity of coat characteristics was evaluated based on Euclidean distances between features in the SSPS program. Statistical processing was performed in Microsoft Excel 2007.

Results. The proportion of down fibers and their thickness in the Pamir fine-wooled sheep was $98.53 \pm 0.06 \%$ and $20.81 \pm 0.23$ microns, the Values of these indicators in the Pamir fine-wool hybrids were $92.31 \pm 0.13 \%$ and $21.90 \pm 0.24$ microns. Cluster analysis of the similarity of wool cover characteristics in sheep of the studied genotypes based on the calculation of Euclidean distances, performed in the SPSS program, revealed two clusters. The first cluster is formed by sheep of the Pamir fine-wool breed and their descendants from a hybrid carrying $1 / 4$ of the argali blood and $3 / 4$ of the Romanov sheep blood. The second cluster includes the remaining sheep genotypes. Within this cluster, a subcluster is allocated that unites argali (argali) and its hybrids of two generations. Within the subcluster, the argali and its first-generation hybrid with the Romanov sheep are the closest.
\end{abstract}

Поступила: 8 июля

После доработки: 9 сентября

Принята к публикации: 10 сентября
Received: 8 july

Revised: 9 september

Accepted: 10 september 


\section{Введение}

На сегодняшний день в мире в силу действия ряда антропогенных факторов идет интенсивный процесс сокращения численности и исчезновения культурных пород, типов и линий животных (Столповский Ю.А. и др., 2017). По оценке экспертов ФАО за период с 2005-го по 2014 годы доля пород, находящихся под угрозой исчезновения, возросла с 15 до 17\%. Кроме того, статус 58\% пород не известен (ФАО, 2015). В сложившейся ситуации остро стоит вопрос не только сохранения имеющихся генетических ресурсов, но и компенсации произошедших потерь путем создания новых адаптированных к местным условиям форм сельскохозяйственных животных.

Одним из путей повышения генетического разнообразия и создания новых возможностей для получения новых селекционных форм, наиболее полно отвечающих требованиям рынка, является использование аллелофонда родственных диких видов животных, в том числе архара (O. ammon L., 1758) посредством их гибридизации с домашними видами (Багиров В.А. и др. 2004; 2009).

Новые селекционные формы овец, полученные посредством отдаленной гибридизации с архаром, обладают повышенными адаптивными качествами, характерными для архара, такими как устойчивость к сложным географическим и природно-климатическим условиям окружающей среды, низкому содержанию кислорода, скудному рациону (Jueken, А. 2012; Jueken, A, Hubdar, S.Yiming, Q, 2011; L. Li, M. Guilin, Y. Qin, G. D. Ji, C. Lan, Y. Xi, Z. Hongxia, Y. Hai, Z. Fang, W. 2014; Багиров, В.A. и др, 2015). При этом сочетают ценные адаптивные качества с полезными продуктивными свойствами. Известно, что гибридные животные наследуют ценные продуктивные качества, обусловленные специфическими генетическими характеристиками архара (L. Li, G.D. Ji, Y. Xi, Y. Hai, W. Zhiping, Z. Yuanfang 2015).

В овцеводстве, наряду с мясной, важную роль играет шерстная продуктивность. В силу своих технологических качеств шерсть является уникальным сырьем для легкой промышленности, которое не заменят ни искусственные, ни синтетические волокна. Неслучайно после наблюдавшегося в мире длительного спада производства шерсти в последнее десятилетие наметился его рост. При этом несомненный интерес представляет состав шерстного покрова, поскольку наличие в руне волокон разного диаметра определяет технологическое назначение шерсти. От этого показателя в определенной степени зависит и величина шерстной продуктивности овец. В связи чем представляет интерес, какое влияние гибридизация с дикими видами окажет на качество шерсти тонкорунных овец.

Целью настоящего исследования явилось изучение параметров шерстного волокна у потомков тонкорунных овец, полученных от гибрида, несущего 1/8 крови архара в сравнении с исходными формами.

\section{Материал и методы}

Исследование выполнено в Федеральном научном центре Всероссийский институт животноводства. В настоящей работе мы проанализировали особенности по тонине шерстных волокон разных типов, а также структуре руна у архара (O. ammon
L., 1758) овец романовской породы (O. aries L., 1758) и их гибридов, несущих 1/4 и 1/8 крови архара, овец памирской тонкорунной породы (O. ammon L., 1758) и овецот гибрида 3/4 Романовская (РОМ) × 1/4 Архар (АРX).

Анализировали качество шерсти у 5 гибридных баранчиков памирской тонкорунной породы. В качестве контроля исследовали 10 чистопородных сверстников памирской тонкорунной породы. Отбор проб и исследование шерсти проводили в соответствие с ГОСТ 17514-93. У каждого животного для формирования средней пробы брали по 5 точечных проб (штапель) из разных мест руна. Для анализа отбирали 1/3 средней пробы, промывали ее в мыльно-содовом растворе, высушивали при 60-70 ${ }^{\circ} \mathrm{C}$ и расчесывали на чесальном валике. Чтобы определить долю волокон разного типа (пух, переходный тип, ость) в образце анализировали не менее 500 волокон от каждого животного. Диаметр волокон измеряли под микроскопом при увеличении 40×, не менее 300 волокон для каждого типа.

Животных стригли весной 2018 года по достижении ими годовалого возраста. Образцы шерсти гибридного барана-производителя (3/4 POM × 1/4 APX), его отца гибрида APF1 (1/2 POM × 1/2 APX), архара и 5 романовских овец отбирали в это же время на физиологическом дворе ФНЦ ВИЖ. Сравнивали состав руна, тонину шерсти половозрелых овец

Обработку данных проводили с использованием пакета программ Microsoft Exel, IBM SPSS Statistics 23. Сравнение овец исследуемых генотипов осуществляли методом иерархической кластеризации.

\section{Результаты и обсуждение}

В таблице 1 приведены данные о доле шерстных волокон разного типа в исследованных группах овец.

Из приведенных в таблице 1 данных видно, что овцы романовской породы и архар достоверно различаются как по частоте пуховых, так и остевых волокон $(p<0,001)$, но имеют одинаковую долю переходных волокон.

Аналогично оба варианта гибридов романовской породы овец с архаром также различаются между собой достоверно только по долям пуховых и переходных волокон $(p<0,05)$.

Максимальная доля пуховых волокон - 98,5\% была выявлена у памирских тонкорунных овец. Их гибриды (ПТП + 3/4 РОМ + 1/2 АРХ) уступали чистопородным сверстникам по доле пуховых волокон на 6,2\% $(p<0,001)$ и достоверно превосходили их на ту же величину по доле переходных волокон $(p<0,001)$. Остевые волокна у овец этих двух генотипов отсутствовали. 
Table 2. Thickness of different types of wool fibers in sheep of different genotypes

\begin{tabular}{|l|c|c|c|}
\hline & \multicolumn{3}{|c|}{ Голщина шерстных волокон в мкм } \\
\hline \multicolumn{1}{|c|}{ Генотип } & пух & переходные & ость \\
\hline Архар (АРХ) & $28,80 \pm 1,17$ & $83,08 \pm 1,09$ & $135,65 \pm 2,44$ \\
\hline Романовская порода (РОМ) & $19,95 \pm 0,32$ & $49,28 \pm 0,62$ & $63,27 \pm 1,38$ \\
\hline 1/2 РОМ + 1/2 АРХ & $17,35 \pm 0,42$ & $75,47 \pm 0,97$ & $117,86 \pm 2,08$ \\
\hline 3/4 РОМ + 1/4 АРХ & $27,56 \pm 0,72$ & $59,52 \pm 0,48$ & $79,78 \pm 2,67$ \\
\hline $\begin{array}{l}\text { Памирская тонкорунная порода } \\
\text { (ПТП) }\end{array}$ & $20,81 \pm 0,23$ & $39,00 \pm 1,33$ & 0 \\
\hline ПТП + 3/4 РОМ + 1/4 АРХ & $21,90 \pm 0,24$ & $42,00 \pm 1,84$ & 0 \\
\hline
\end{tabular}

Рис. 1. Дендрограмма сходства изученных групп животных по доле пуховых волокон и тонине шерстных волокон разного типа

Fig. 1. Dendrogram of the similarity of the studied groups of animals in the proportion of down fibers and fineness of wool fibers of different types

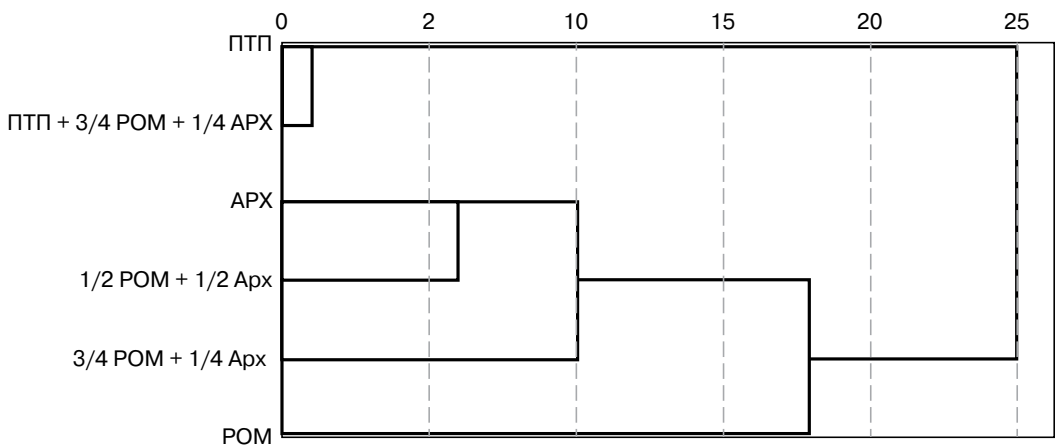

различия в тонине волокон отмечены у обоих вариантов гибридов романовской породы овец с архаром $(p<0,001)$. По тонине пуховых и переходных волокон у памирских тонкорунных овец и их гибридов достоверные различия отсутствовали.

Для сравнительного анализа у исследуемых групп животных на основании приведенных в таблицах 1 и 2 данных была проведена оценка сходства шерстного покрова по доле пуха и тонине волокон разного типа. Кластерный анализ сходства характеристик шерстного покрова у овец исследованных генотипов, основанный на расчете евклидовых расстояний между признаками, выполненный в программе SPSS, показал, что исследованные генотипы делятся на два кластера. В первый кластер входят овцы памирской тонкорунной породы (ПТП) и их помеси с гибридом второго поколения архара и романовской овцы $\left(П Т П \times \mathrm{F}_{2}\right)$. Во второй кластер входят остальные генотипы. Внутри этого кластера выделяется подкластер, объединяющий архара (архар) и его гибридов двух поколений. В пределах подкластера наиболее близки архар и его гибрид первого поколения с романовской овцой (F1). К этой группе генотипов примыкает романовская овца (романовская), завер-

По доле пуховых волокон чистопородные памирские тонкорунные овцы и их гибриды достоверно превосходили овец остальных генотипов ( $p<0,001)$. По доле переходных волокон они достоверно уступали овцам остальных групп $(p<0,001)$.

Из приведенных в таблице 2 данных видно, что овцы романовской породы и архар достоверно различаются по тонине всех типов волокон $(p<0,001)$. Аналогичные шающая второй кластер (рис.).

Необходимо отметить, что к помесям ПТПхF2, помимо чистопородных памирских тонкорунных овец, оказался близок архар, в целом же структура дендрограммы согласуется с данными о генетических связях между сравниваемыми группами. Полученные данные свидетельствуют о возможности скрещивания гибридов архара с тонкорунными овцами

\section{ЛИТЕРАТУРА}

1. Столповский Ю.А., Захаров-Гезехус И.А. Проблема сохранения генофондов доместицированных животных. Вавиловский журнал генетики и селекции. 2017;21(4):477-486.

2. ФАО. Второй доклад о состоянии мировых генетических ресурсов животных для производства продовольствия и ведения сельского хозяйства. Краткое изложение. Рим: ФАО, 2015. $14 \mathrm{c}$.

3. Багиров В.А., Эрнст Л.К., Кленовицкий П.М., Зиновьева Н.А. Сохранение генетических ресурсов редких, исчезающих и уникальных видов животных. Цитология. 2004;4(9):767-768.

4. Багиров, В.А., Эрнст Л.К., Насибов Ш.Н., Кленовицкий П.М., Иолчиев Б.С., Зиновьева Н.А. Сохранение биоразнообразия животного мира и использование отдаленной гибридизации в животноводстве. Достижения науки и техники АПК. 2009. №7.

\section{REFERENCES}

1. Stolpovsky Yu.A., Zakharov-Gezekhus I.A. The problem of preserving the gene pools of domesticated animals. Vavilov Journal of Genetics and Breeding. 2017;21(4):477-486. (In Russ.)

2. FAO. Second Report on The State of the World's Animal Genetic Resources for Food and Agriculture. Summary. Rome: FAO, 2015.14 p. (In Russ.)

3. Bagirov V.A., Ernst L.K., Klenovitsky P.M., Zinovieva N.A.
5. Jueken, A., Kumunisihan J., Hamiti H., Yiming S. Alalysis on Adaptability of Hybrid Offspring of Wild Argali and Bashibai Sheep. Journal of Xinjiang Agricultural University. 2012. №2.

6. Jueken, A., Hubdar A.K., Yiming S., Li Q., Xie Z. Comparative analysis on the performance of the hybrid offspring of wild argali and Bashibay sheep. African Journal of Biotechnology. 2011;10(28):5539-5544, DOI: 10.5897/AJB10.1542.

7. Li, L., , G.D. Ji, Y. Xi, Y. Hai, W. Zhiping, Yuanfang Z. Laws of development and the Half-Blood wild argali sheep Euler F1 hybrids growth. Journal of Animal Science and Veterinary Medicine. 2015. V.1.

8. Li, L., M. Guilin, Y. Qin, G. D. Ji, C. Lan, Y. Xi, Z. Hongxia, Y. Hai, Z. Fang, Zhiping W. 25 And a half of blood wild argali ram introduction and adaptive observation. Animal Husbandry and Veterinary Medicine Article. 2014. №6.

Conservation of genetic resources of rare, endangered and unique animal species. Cytology. 2004;4(9):767-768. (In Russ.)

4. Bagirov, V.A., Ernst L.K., Nasibov Sh.N., Klenovitsky P.M. lolchiev B.S., Zinovieva N.A. Conservation of biodiversity of fauna and the use of distant hybridization in animal husbandry. Achievements of science and technology of the agro-industrial complex. 2009;7. (In Russ.)

5. Jueken,·A., Kumunisihan J., Hamiti H., Yiming S. Alalysis on 
Adaptability of Hybrid Offspring of Wild Argali and Bashibai Sheep. Journal of Xinjiang Agricultural University. 2012;2.

6. Jueken, A , Hubdar A.K Y, Yiming S, Li Q, Xie Z, Comparative analysis on the performance of the hybrid offspring of wild argali and Bashibay sheep. African Journal of Biotechnology. 2011;10(28):5539-5544, DOI: 10.5897/AJB10.1542.

7. Li, L., , G.D. Ji, Y. Xi, Y. Hai, W. Zhiping, Yuanfang Z. Laws of

\section{ОБ АВТОРАХ:}

Кленовицкий Павел Михайлович, доктор биологических наук, профессор, ведущий научный сотрудник

Иолчиев Байлар Садраддинович, доктор биологических наук, ведущий научный сотрудник

Волкова Наталья Александровна, доктор биологических наук, зав. Лабораторией

Раджабов Наджбуддин Амиралиевич, кандидат сельскохозяйственных наук, докторант. development and the Half-Blood wild argali sheep Euler F1 hybrids growth. Journal of Animal Science and Veterinary Medicine. $2015 ; 1$.

8. Li, L., M. Guilin, Y. Qin, G. D. Ji, C. Lan, Y. Xi, Z. Hongxia, Y. Hai, Z. Fang, Zhiping W. 25 And a half of blood wild argali ram introduction and adaptive observation. Animal Husbandry and Veterinary Medicine Article. 2014;6.

\section{ABOUT THE AUTHORS:}

Klenovitsky Pavel Mikhailovich, doctor of biological sciences, professor, leading researcher

lolchiev Baylar Sadraddinovich, doctor of biological sciences, leading researcher

Volkova Natalya Aleksandrovna, doctor of biological sciences, head of laboratory

Rajabov Najbuddin Amiralievich, candidate of agricultural sciences, doctoral student.

\section{НОВОСТИ•НОВОСТИ•НОВОСТИ•НОВОСТИ॰}

\section{Овцеводы Ставропольского края продемонстрировали результаты своей работы}

В сентябре двухдневный тур по ведущим племенным хозяйствам Ставропольского края, занимающимся разведением овец российского мясного мериноса и других тонкорунных пород мясо-шерстного направления, организовали Всероссийский НИИ овцеводства и козоводства и Национальный союз овцеводов России. За передовым опытом приехали представители Дагестана, Калмыкии, Краснодарского края и других овцеводческих регионов страны. За два дня овцеводы ознакомились с работой 7 племенных организаций, расположенных в различных районах Ставропольского края. В частности, осмотрели поголовье племенных баранов породы «Российский мясной меринос» - новой отечественной породы овец. По словам дагестанских специалистов, с привлечением этой породы в РД успешно проходят эксперименты по улучшению мясо-шерстных качеств овец дагестанской горной породы. Помесное поголовье демонстрирует хорошую приспособленность к условиям отгонного животноводства, наилучшую мясную и шерстную продуктивность. Использование в воспроизводстве стада высокопродуктивных баранов-производителей - важнейшее условие повышения продуктивности, улучшения качественного состава стада, отметили овцеводы.

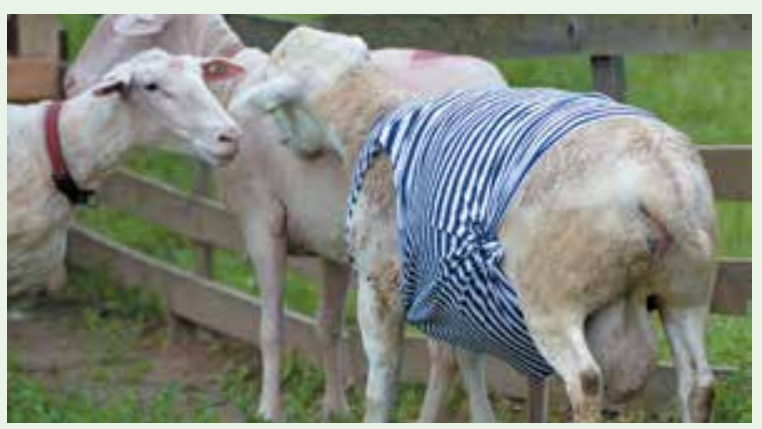

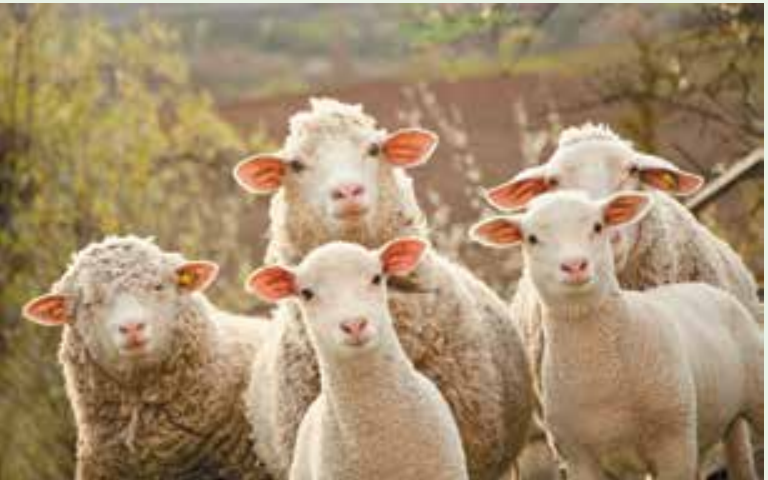

\section{В Хакассии внедряется республиканская программа поддержки овцеводства}

В сельскохозяйственном институте Хакасского госуниверситета завершились бесплатные курсы по дополнительной программе «Технологии искусственного осеменения овец». Их участниками стали руководители и работники фермерских и коллективных хозяйств республики. В рамках курсов специалисты узнали о подготовке самок к воспроизводству, качестве семени, организации пункта искусственного осеменения овец и технологии осеменения. Применение искусственного осеменения дает возможность контролировать туровый окот, улучшает мясные и породные качества животных. В рамках обучения овцеводы прошли практический курс в селе Краснополье Алтайского района, у владельцев крестьянско-фермерского хозяйства Поздняковых, единственного в Сибири, где занимаются разведением овец знаменитой романовской породы. Краткосрочные курсы осеменаторов стали первым этапом республиканской программы поддержки овцеводства. В частности, с будущего года хозяйства, занятые разведением овец путем искусственного осеменения, будут получать субсидию в размере 500 руб. за каждого ягненка. 